\title{
A pesquisa em educação ambiental nos EPEAs (2001- 2007): natureza dos trabalhos, contextos educacionais e focos temáticos
}

\author{
Clarice Sumi Kawasaki1; Luiz Marcelo de Carvalho²; Antonio \\ Vitor Rosa ${ }^{3}$; Dalva Maria Bianchini Bonotto²; Haydée Torres de \\ Oliveira ; Heloísa Sisla Chalmers Cinquetti4; Luiz Carlos Santana ${ }^{2}$ \\ e Rosa Maria Feiteiro Cavalari²
}

Resumo: O emergente campo da pesquisa em educação ambiental (EA) no Brasil traz a necessidade de uma sistematização dessa produção a fim de identificar e configurar aspectos desse novo campo do conhecimento. O presente trabalho visa contribuir nessa direção a partir da análise dos trabalhos apresentados nos Encontros de Pesquisa em Educação Ambiental (EPEAs). Os resultados apontam a predominância de trabalhos de natureza empírica em relação aos de natureza teórica e reflexiva e de trabalhos relacionados a contextos educacionais escolares em relação a contextos não escolares, sendo os níveis escolares fundamental e médio os mais presentes. Em relação aos trabalhos de natureza teórica e reflexiva, há predominância dos fundamentos teóricos e metodológicos da EA como foco temático. Já entre os trabalhos de natureza empírica, o principal foco temático é o desenvolvimento de projetos, programas e práticas em contextos escolares ou não escolares. Há ainda um número bastante significativo de trabalhos com contextos educacionais não específicos, nos quais predominam como focos temáticos os processos formativos e as concepções de professores e educadores. Aspectos referentes à avaliação dos trabalhos submetidos aos EPEAs também são destacados neste artigo.

Palavras-chave: Educação Ambiental, Encontros de Pesquisa, Avaliação, Natureza dos Trabalhos, Contextos Educacionais, Focos Temáticos.

Abstract: The emerging field of environmental education (EE) research in Brazil requires a systematization of its production so that its aspects can be identified and set up. This work aims to contribute in that sense based on the analysis of the works presented at the Research Meetings on Environmental Education (EPEAs). The results indicate the predominance of works of theoretical nature over the ones of empirical nature, as well as the predominance of works related to school contexts in comparison to works related to non-school contexts, the

1 Professora do depto. de Psicologia e Educação / FFCLRP/USP. Contato: Av. Bandeirantes, 3900. Monte Alegre, Rib. Preto - SP CEP14040-901 e-mail: sumi@ffclrp.usp.br.

${ }^{2}$ Professor (a) do Instituto de Biociências / Universidade Estadual Paulista (UNESP-Rio Claro)

${ }^{3}$ Educador do Depto.de Psicologia e Educação / FFCLRP / USP

${ }^{4}$ Professora da Universidade Federal de São Carlos 
former focusing especially on elementary and secondary education. Regarding the works of theoretical nature, the theoretical and methodological bases of EE are the most frequent thematic focus. Among the works of empirical nature, the main thematic focus is the development of projects, programs and practices in school or non-school contexts. There are also a significant number of works related to non-specific educational contexts, in which education processes and teachers' and educators' conceptions prevail as thematic focuses. Some aspects concerning the evaluation of the works submitted to the EPEAs are pointed out in this paper as well.

Keywords: Environmental Education, Research Meetings, Evaluation, Nature of Works, Educational Contexts, Thematic Focuses.

\section{Introdução}

Em 2000, pesquisadores ligados a três universidades públicas do estado de São Paulo, motivados pela necessidade de compartilhar e discutir as pesquisas em educação ambiental (EA), iniciaram discussões sobre a realização de um encontro específico com tal propósito. Nos parágrafos seguintes, delineamos sucintamente o percurso da pesquisa nessa área, em particular no Brasil, para em seguida indicar o papel desempenhado pelo EPEA e os objetivos deste trabalho.

A partir da década de 1970, cresceu o reconhecimento quanto à importância e aos significados atribuídos às práticas educacionais relacionadas às questões ambientais, não só para podermos compreender as causas e consequências dos problemas ambientais mas também para construirmos novos padrões éticos e políticos que nos ofereçam caminhos alternativos aos atuais padrões de relação sociedade-natureza. As expectativas quanto às possibilidades do processo educativo frente à temática ambiental, muitas vezes, apresentam-se como um quadro de "entusiasmo exagerado pela educação ambiental", evidenciando interpretações ingênuas a respeito do seu papel nesse contexto. De qualquer forma, uma variedade de programas, projetos e atividades de EA foi, a partir de então, promovida pelo país, seja em contexto escolar, seja em outros contextos educacionais. É importante, no entanto, considerarmos que, a despeito de posições permeadas por um exagerado otimismo pedagógico, não podemos deixar de reconhecer que o processo educativo, em uma perspectiva não ingênua e consciente de suas possibilidades e limites, pode ser tomado, entre outras práticas sociais, como um caminho para alterar o modo como as sociedades têm se relacionado com a natureza.

Foi a partir do início da década de 1990 que se evidenciou a necessidade de sistematizar as experiências acumuladas e de esclarecer os pressupostos teóricos que subsidiam uma discussão mais aprofundada dessas práticas de EA. 
A demanda por processos de investigação científica que respondam às múltiplas e complexas questões referentes à temática ambiental e suas possíveis relações com o processo educativo emergiu no país e apontou uma produção científica brasileira nessa área, já bastante significativa e com certa especificidade, expressa em diversos programas de pós-graduação e instituições de pesquisa (CARVALHO; TOMAZELO; OLIVEIRA, 2009). Investigações dedicadas a analisar a produção da pesquisa em EA no Brasil são unânimes em apontar a "explosão vertiginosa" em relação ao número de dissertações e teses sobre essa temática, produzidas nos últimos 10 anos (FRACALANZA, 2004; FRACALANZA et al., 2005; GRANDINO; TOMAZELO, 2007; REIGOTA, 2007; TOMAZELO, 2005). É bastante significativo o envolvimento da comunidade acadêmica brasileira no processo de produção do conhecimento científico relacionado à EA, em diferentes campos do conhecimento e espaços institucionais. Os variados cursos de pós-graduação têm oferecido possibilidades para a realização de trabalhos tanto em linhas específicas de pesquisa em EA quanto em áreas correlatas. É interessante observar, por exemplo, o número crescente de teses, dissertações e artigos em revistas especializadas analisando programas, projetos e atividades educativas e produzindo conhecimento relacionado a diferentes abordagens em EA. Há ainda pesquisas sendo desenvolvidas fora dos programas de pós-graduação, em instituições não universitárias, tanto em órgãos governamentais (Secretarias do Meio Ambiente, IBAMA, jardins botânicos, zoos e outros) como em instituições não governamentais (ONGs).

Apesar desse quadro de produção da pesquisa em EA no nosso país, há ainda poucos espaços para o compartilhamento dos conhecimentos que vêm sendo produzidos por essa comunidade de pesquisadores. São igualmente escassas as iniciativas de sistematização e reflexão dessa própria produção. Sistematizar e discutir os resultados dessas pesquisas permite criar mecanismos de socialização dos mesmos e contribuir para evitar interpretações ingênuas e perspectivas exclusivamente pragmáticas, muitas vezes presentes no movimento ambientalista mais amplo e nas iniciativas de EA.

Assim, o EPEA, como outros esforços de socialização e discussão da pesquisa no país, tem cumprido um papel de grande significado nesse contexto oferecendo à comunidade de pesquisadores um espaço acadêmico para a discussão da pesquisa em EA. No caso específico desse evento, os objetivos que têm norteado a sua organização e condução podem ser assim sistematizados:

- Discutir, analisar e divulgar trabalhos de pesquisa em EA;

- Aprofundar as discussões sobre as abordagens epistemológicas e metodológicas das pesquisas em EA; 
- Identificar práticas de pesquisa em EA que vêm sendo desenvolvidas no âmbito dos programas de pós-graduação e em outros espaços institucionais e não institucionais.

Por ser um evento científico de caráter interinstitucional que envolve em sua organização pesquisadores de três universidades públicas paulistas Faculdade de Filosofia, Ciências e Letras de Ribeirão Preto, da Universidade de São Paulo (FFCLRP/USP), Universidade Estadual Júlio de Mesquita Filho (UNESP), Campus de Rio Claro, e Universidade Federal de São Carlos (UFSCar) (Tabela 1) -, o EPEA tem sido realizado por meio de um sistema de rodízio nos municípios nos quais essas instituições se localizam.

Nesta trajetória, o EPEA tem contado com o respaldo de pesquisadores de diferentes regiões do país, de importantes instituições de apoio à pesquisa, como CAPES, FAPESP, FUNDUNESP, e dos programas de Pós-Graduação em Educação, em Ecologia e Recursos Naturais e em Engenharia Ambiental das instituições organizadoras.

As temáticas dos EPEAs (Tabela 1) refletem a diversidade própria da constituição do campo da EA, integrando diferentes áreas do conhecimento. Há uma preocupação em realizar sessões de trabalho que desenvolvam reflexões de cunho filosófico, epistemológico, teórico e metodológico e, por isso, busca-se convidar para as conferências e mesas-redondas intelectuais, pensadores, filósofos e pesquisadores que elaboram reflexões mais amplas, não vinculadas apenas às especificidades da educação ambiental ou da pesquisa em educação ambiental.

O público participante, nos quatro eventos realizados, manteve-se estável, tendo em média 281 pesquisadores, com exceção do III Encontro, no qual ocorreu um aumento significativo (33\%) em relação a essa média. Quanto ao número de estados brasileiros, podemos observar uma participação média de 20 estados da Federação. De qualquer forma, apesar de a região Sudeste concentrar o maior número de participantes, identificam-se representantes de todas as regiões brasileiras, o que reflete a abrangência e o significado desse evento no país. Percebe-se ainda ao longo dos encontros uma tendência de crescimento na participação das regiões Sul e Centro-Oeste.

Em relação ao número de trabalhos submetidos nos quatro eventos $(\mathrm{N}$ = 598), verifica-se uma variação com tendência crescente do primeiro ao último evento, sendo a média de 149,5 trabalhos/evento. 
Tabela 1 - Encontros de Pesquisa em Educação Ambiental (EPEAs) realizados entre 2001 e 2007 - ano, instituição, tema, $\mathrm{n}^{\circ}$ de inscritos/estados e $\mathrm{n}^{\mathrm{o}}$ de trabalhos submetidos.

\begin{tabular}{|c|c|c|c|c|}
\hline ANO & INSTITUIÇÃO & TEMA & $\begin{array}{c}\text { N } \\
\text { INSCRIÇÕES/ } \\
\text { ESTADOS }\end{array}$ & $\begin{array}{c}\mathbf{N}^{\mathbf{0}} \text { DE } \\
\text { TRABALHOS } \\
\text { SUBMETIDOS }\end{array}$ \\
\hline $\begin{array}{c}\text { I EPEA } \\
\mathbf{2 0 0 1}\end{array}$ & $\begin{array}{c}\text { UNESP } \\
\text { RIO CLARO }\end{array}$ & $\begin{array}{c}\text { TENDÊNCIAS E } \\
\text { PERSPECTIVAS }\end{array}$ & $298 / 22$ & 116 \\
\hline $\begin{array}{c}\text { II EPEA } \\
\mathbf{2 0 0 3}\end{array}$ & $\begin{array}{c}\text { UFSCAR } \\
\text { SÃO CARLOS }\end{array}$ & $\begin{array}{c}\text { EPISTEMOAOLOGICAS E } \\
\text { METODOLÓGICAS }\end{array}$ & $280 / 21$ & 140 \\
\hline $\begin{array}{c}\text { III EPEA } \\
\mathbf{2 0 0 5}\end{array}$ & $\begin{array}{c}\text { USP } \\
\text { PREIRÃO }\end{array}$ & $\begin{array}{c}\text { PRÁTICAS DE PESQUISA EM } \\
\text { ERA }\end{array}$ & $376 / 21$ & 116 \\
\hline $\begin{array}{c}\text { IV EPEA } \\
\mathbf{2 0 0 7}\end{array}$ & UNESP & $\begin{array}{c}\text { O DEBATE MODERNIDADE E } \\
\text { PIOS-MODERNIDADE }\end{array}$ & $266 / 15$ & 226 \\
\hline
\end{tabular}

Assim, no intuito de contribuir para a construção de um quadro sobre a pesquisa em EA no nosso país, somando esforços a outras iniciativas nessa direção, este trabalho apresenta e analisa o universo das pesquisas em EA que foram aprovadas e publicadas nos anais dos quatro primeiros EPEAs, em relação aos seguintes aspectos: a) a natureza das pesquisas; b) os contextos educacionais a que se referem e c) os focos temáticos privilegiados nas mesmas.

Análises realizadas sobre os trabalhos apresentados no I EPEA encontram-se publicadas no primeiro número desta revista (v.1, n.1, 2006). Tais artigos buscaram identificar as tendências e perspectivas da pesquisa em EA a partir da identificação de concepções de educação (CAVALARI; SANTANA; CARVALHO, 2006), das abordagens metodológicas utilizadas nas pesquisas apresentadas (FREITAS; OLIVEIRA, 2006) e do perfil dos participantes do EPEA (KAWASAKI; MATOS; MOTOKANE, 2006).

Outro aspecto relevante desse processo de comunicação das pesquisas refere-se à seleção dos textos submetidos, cujo resultado (trabalhos aprovados para seleção no evento) define o universo objeto da reflexão aqui apresentada. Os trabalhos submetidos aos EPEAs são analisados inicialmente pela Comissão Organizadora do evento quanto aos aspectos formais, de acordo com as normas para a submissão de trabalhos, e quanto ao enquadramento ao escopo do evento. Neste segundo quesito, verifica-se a pertinência dos mesmos em relação ao campo da pesquisa em EA, ou seja, se esses são trabalhos de pesquisa científica ou acadêmica e se esses se encontram no âmbito da EA. Somente os trabalhos aprovados nessa etapa preliminar são submetidos à etapa seguinte, na qual dois pareceristas, doutores experientes em pesquisa em educação e em educação ambiental, convidados para compor a Comissão Científica, fazem a avaliação (no formato de duplo-cego) quanto ao mérito do trabalho. Assim, cada parecerista elabora um parecer circunstanciado no qual são relacionados os argumentos favoráveis ou desfavoráveis à aprovação da apresentação do trabalho no evento. 
Os pareceres são concluídos com a indicação da aceitação ou não aceitação do trabalho. Em caso de não concordância dos pareceres, outro é solicitado a um terceiro parecerista, que não tem conhecimento dos pareceres anteriores, a fim de se obter uma decisão final. Informações mais detalhadas a respeito dos itens de avaliação utilizados encontram-se na ficha de avaliação disponível no sítio do EPEA (www.epea.tmp.br).

\section{Procedimentos da pesquisa}

Para a análise que ora apresentamos, a primeira característica que procuramos identificar refere-se à natureza desses trabalhos. Entre as modalidades de trabalho permitidas para apresentação nos EPEAs, além de relatos de pesquisa, há a possibilidade de envio de ensaios críticos, porém, na presente pesquisa esse grupo de trabalhos foi categorizado como textos teóricos $e$ reflexivos, uma vez que os mesmos não apresentavam elementos suficientes para aquela classificação. Muitos dos textos encaminhados e classificados como "ensaios" são parte de um projeto de pesquisa mais amplo em desenvolvimento e se constituem em textos na forma de revisão bibliográfica ou de uma síntese do referencial teórico-metodológico da pesquisa como um todo, ou mesmo de reflexão sobre um tema que envolve a temática ambiental ou a educação ambiental a partir de certos pressupostos. Dessa forma, dividimos os textos encaminhados em dois grandes grupos: textos teóricos e reflexivos e relatos de pesquisas empiricas.

A pesquisa teórica é aquela que se dedica a reconstruir teorias, conceitos, ideias, ideologias, polêmicas tendo em vista, em termos imediatos, aprimorar fundamentos teóricos (DEMO, 2000). Consideramos importante destacar que, mesmo que tragam referências a experiências concretas, os trabalhos de natureza teórica buscam construir modelos explicativos de maior alcance, estabelecendo diálogos e interlocuções com autores e campos disciplinares diversos.

A pesquisa de natureza empírica, por sua vez, é aquela que se dedica ao tratamento da "face empírica e factual da realidade", produzindo e analisando dados, procedendo sempre pela via do controle empírico e factual (DEMO, 2000). A valorização desse tipo de pesquisa se deve à "possibilidade que oferece de maior concretude às argumentações, por mais tênue que possa ser a base factual. O significado dos dados empíricos depende do referencial teórico, mas estes dados agregam impacto pertinente, sobretudo no sentido de facilitarem a aproximação prática" (DEMO, 1994, p. 37). Assim, trabalhos de natureza empírica são aqueles que, sem necessariamente abrir mão da problematização, caracterizam-se por manter uma maior proximidade com as práticas e experiências dos atores. 
O segundo aspecto analisado diz respeito aos contextos educacionais referidos nas pesquisas, ou seja, analisamos se o foco da investigação estava voltado para o contexto escolar (espaço formal), para o contexto não escolar (espaço não formal ou informal) ou para um contexto educacional não específico, sendo então denominado genérico. Todavia, para a presente pesquisa, esta análise foi feita apenas no conjunto dos trabalhos de natureza empírica, havendo ainda a necessidade de realizá-la no conjunto dos trabalhos de natureza teórica e reflexiva. Ainda em relação aos trabalhos referidos ao contexto escolar, foram identificados os níveis escolares presentes, ou seja, se os trabalhos se situavam na educação básica (infantil, fundamental e/ou média), na educação superior ou em outras modalidades de educação (de jovens e adultos).

Os focos temáticos privilegiados nesses trabalhos constituíram o terceiro aspecto considerado para a análise. Tais focos foram construídos ao longo do processo de análise e complementados por informações obtidas por meio da leitura dos trabalhos aqui analisados. Nesse caso, todos os trabalhos foram analisados.

Para a operacionalização da análise dos 312 trabalhos apresentados nos EPEAs realizamos inicialmente um estudo-piloto com os trabalhos do IV EPEA, no qual o conteúdo de cada artigo foi analisado (BARDIN, 1977) por dois avaliadores, tendo como referência um roteiro para a classificação dos textos com base nos descritores mencionados acima. Em situação de discordância, um terceiro avaliador atuou como árbitro para decidir a respeito das opções de classificação indicadas pelos analistas anteriores. Esse estudopiloto permitiu exercitar a análise propriamente dita e refinar os descritores, no sentido de especificá-los e aperfeiçoá-los. A partir desse estudo-piloto, a classificação de todos os outros trabalhos apresentados nesses encontros seguiu o mesmo procedimento. É importante destacar que em alguns itens de análise, como os níveis educacionais do contexto escolar e os focos temáticos, parte dos trabalhos foi contabilizada mais de uma vez, o que trouxe um total excedente em relação ao universo de trabalhos.

\section{Resultados}

$\mathrm{Na}$ Tabela 2, na qual apresentamos a quantidade de trabalhos encaminhados ao EPEA para avaliação e a quantidade de trabalhos aprovados, podemos observar que há um número bastante significativo de trabalhos que não foram aprovados (47\%). Essa tendência pode ser explicada pelo fato de que, apesar de estar indicado claramente nos meios de divulgação do evento (folder e site) que os trabalhos submetidos deveriam ser de pesquisa, concluídos ou não, foram enviados textos que relatam experiências educacionais de diferentes 
formatos, mas sem a dimensão de pesquisa. Estes eram, em sua maioria, relatos de experiências pedagógicas de indiscutível relevância para a área educacional, porém, com ênfase quase exclusiva em descrições de projetos, materiais e atividades educativas e/ou de ensino que não empreendiam reflexões $\mathrm{e}$ teorizações sobre essas experiências. Tais descrições não se pautavam em quadros teóricos ou metodológicos de referência e tampouco havia explicitação da questão e/ou objetivo norteador da pesquisa. Entre os não aprovados havia, também, projetos de pesquisa em fase inicial, além de programas, materiais didáticos/pedagógicos na forma de propagandas de empresas das áreas ambiental e educacional. Apesar de essa situação ter sido alterada do primeiro ao quarto evento, já que houve um acréscimo de 14,2\% de trabalhos aprovados, é importante destacar que muitas dessas limitações já haviam sido observadas no primeiro evento, conforme apontam Freitas e Oliveira (2006), em relação aos trabalhos analisados:

Aspectos que dariam maior relevância científica são desconsiderados, o que pode ser afirmado com base nas seguintes constatações: desconexão entre a teoria e os resultados encontrados; pouca fundamentação ou incorporação muito superficial dos referenciais teórico-metodológicos; imprecisão dos limites da intervenção educativa e da pesquisa; apresentação dos referenciais da intervenção e apresentação insuficiente dos referenciais da pesquisa; imprecisão e inconsistência no uso de termos e de instrumentos que são apropriados de outras áreas; caráter muito descritivo das pesquisas; uso indevido de fontes de literatura; confusão entre pesquisa qualitativa e quantitativa; instrumentos pouco consistentes para a coleta de dados (FREITAS; OLIVEIRA, 2006, p. 183).

Tabela 2 - Número de trabalhos submetidos e aceitos para apresentação nos EPEAs (2001 a 2007).

\begin{tabular}{|c|c|c|}
\hline EVENTO & N $^{\circ}$ DE TRABALHOS SUBMETIDOS & N $^{\circ}$ DE TRABALHOS ACEITOS \\
\hline I EPEA (2001) & 116 & 77 \\
\hline II EPEA (2003) & 140 & 73 \\
\hline III EPEA (2005) & 116 & 74 \\
\hline IV EPEA (2007) & 226 & 88 \\
\hline TOTAL & 598 & 312 \\
\hline
\end{tabular}

Dos 312 trabalhos aceitos (Tabela 3), a grande maioria (81\%) foi classificada como de natureza empírica e apenas 19\% foram classificados como de natureza teórica e reflexiva. Os trabalhos de natureza empírica buscavam, de modo geral, compreender o significado de dados empíricos e factuais à luz de 
diferentes referenciais teóricos, além de uma aproximação maior com as práticas e experiências dos atores presentes nesses contextos. É possível observar que, enquanto os trabalhos de natureza empírica mantinham-se em torno de uma média de 62,3 trabalhos/evento, os trabalhos de natureza teórica e reflexiva tiveram um aumento expressivo (50\%) do primeiro para o quarto evento. Tendência oposta foi encontrada por Pato, Sá e Catalão (2009) no mapeamento que realizaram sobre as tendências na produção acadêmica em EA a partir dos trabalhos apresentados nas Reuniões Anuais da ANPEd (Associação Nacional de Pós-Graduação e Pesquisa em Educação) entre os anos de 2003 e 2006.

Tabela 3 - Natureza dos trabalhos apresentados nos EPEAs (2001 a 2007).

\begin{tabular}{|c|c|c|c|c|c|}
\hline $\begin{array}{c}\text { NATUREZA DOS } \\
\text { TRABALHOS }\end{array}$ & I & II & III & IV & Total \\
\hline $\begin{array}{c}\text { TEÓRICO- } \\
\text { REFLEXIVA }\end{array}$ & 16 & 8 & 15 & 24 & $63 \downarrow$ \\
\hline EMPIRICA & 65 & 63 & 58 & 63 & $249 \uparrow$ \\
\hline
\end{tabular}

Quanto aos contextos educacionais (Tabela 4), há uma nítida predominância de trabalhos desenvolvidos em contextos escolares $(63,2 \%)$ em relação a contextos não escolares $(30 \%)$ e genéricos $(6,7 \%)$. Apesar da grande expressividade e relevância dos trabalhos relacionados a contextos escolares, verificou-se um aumento $(31,5 \%)$, do primeiro ao quarto evento, de trabalhos de contextos não escolares. Além disso, no cômputo geral, a somatória de trabalhos sobre contextos não escolares e genéricos $(36,7 \%)$ é bastante significativa. Tais resultados apontam a gradativa ampliação do escopo dos objetos de pesquisa em EA, que busca produzir e sistematizar conhecimentos em outros espaços educacionais para além do escolar, como parques, zoológicos, espaços urbanos, etc., além de incluir novos atores, como comunidades, associações de bairro, educadores ambientais, etc.

Tabela 4 - Contexto educacional dos trabalhos de natureza empírica.

\begin{tabular}{|c|c|c|c|c|c|}
\hline CONTEXTO EDUCACIONAL & I & II & III & IV & Total \\
\hline ESCOLAR & 48 & 48 & 40 & 41 & 177 \\
\hline NÃO ESCOLAR & 19 & 23 & 17 & 25 & 84 \\
\hline GENÉRICO & 8 & 0 & 7 & 4 & 19 \\
\hline
\end{tabular}


Quanto aos níveis escolares (Tabela 5), a grande maioria dos trabalhos refere-se à educação básica (82,4\%), o que significa que outros níveis escolares, como a educação superior $(16,9 \%)$ e a educação para jovens e adultos $(0,7 \%)$, estão muito pouco representados. Como mencionado, há trabalhos que se referem a mais de um nível escolar, sendo contabilizados mais de uma vez.

Em relação à educação básica, vale destacar a predominância de trabalhos que focalizam a EA nos ensinos fundamental e médio, perfazendo $97,2 \%$ dos trabalhos; a educação infantil é abordada por apenas 2,8\% dos trabalhos. Tais dados demonstram que há um baixo interesse na educação infantil e na educação para jovens e adultos, expondo uma contradição entre o discurso geral da EA, que enfatiza a necessidade de desenvolver práticas educacionais voltadas para todos os públicos e níveis escolares.

Tabela 5 - Níveis escolares dos trabalhos em contextos escolares em cada EPEA.

\begin{tabular}{|c|c|c|c|c|c|}
\hline NÍVEIS ESCOLARES & I & II & III & IV & Total \\
\hline Educação Básica & 38 & 40 & 34 & 34 & 146 \\
\hline Ensino Superior & 10 & 8 & 6 & 6 & 30 \\
\hline Educ. de Jovens e Adultos & 0 & 0 & 0 & 1 & 1 \\
\hline \multicolumn{2}{|c|}{ Total } \\
\hline
\end{tabular}

Os focos temáticos foram identificados tanto entre os trabalhos de natureza teórica e reflexiva (Tabela 6) como entre os trabalhos de natureza empírica (Tabela 7). Como os trabalhos de natureza empírica foram anteriormente classificados em relação aos contextos educacionais - escolares, não escolares e genéricos -, foi feito um cruzamento entre esses dois aspectos na análise desses trabalhos.

Entre os trabalhos de natureza teórica e reflexiva, foi possível verificar a predominância do foco temático fundamentos teóricos e metodológicos da EA $(61,9 \%)$. Há também um número significativo de trabalhos $(17,5 \%)$ que focalizam as implicações pedagógicas do uso de estratégias e/ou modalidades didáticas - tais como trilhas interpretativas, estudos do meio, atividades de campo, etc. - para a EA. Tais resultados apresentam-nos um cenário otimista para o campo da pesquisa em EA, no qual se percebe uma valorização da discussão teórica e do diálogo entre teorias e práticas educacionais, um aspecto que há bem pouco tempo vem merecendo destaque nesse campo de pesquisa. A busca de relação entre essas práticas educacionais e os modelos ou tendências pedagógicas e a preocupação com a formação de professores/educadores (ambientais), a partir de uma reflexão 
teórica, é também um avanço para esse campo, dado que tais aspectos são, via de regra, abordados nos trabalhos de natureza empírica.

As relações entre movimentos sociais e a EA aparecem timidamente nesses trabalhos, sendo tal foco temático inexistente no conjunto de trabalhos empíricos. Percebe-se aí uma contradição histórica, já que a EA, no mundo e no Brasil, nasceu no interior dos movimentos sociais ligados ao meio ambiente, de modo que se esperaria uma quantidade mais significativa de trabalhos oriundos desse contexto. Provavelmente, a ausência desses trabalhos nos EPEAs se deve à própria característica do encontro, que reúne instituições universitárias, apresentando, portanto, um perfil de participantes pertencentes ao meio acadêmico e universitário (KAWASAKI; MATOS; MOTOKANE, 2006). Entendemos que a ausência de setores e atores da sociedade para além da academia e da universidade é um desafio que deve ser enfrentado na organização dos próximos eventos se queremos, de fato, formar uma comunidade suficientemente diversa que seja capaz de integrar as diferentes áreas do conhecimento que contribuem para esse campo de pesquisa.

Tabela 6 - Focos temáticos dos trabalhos de natureza teórica e reflexiva.

\begin{tabular}{|l|r|r|r|r|r|}
\hline FOCOS TEMÁTICOS & \multicolumn{1}{|c|}{ I } & \multicolumn{1}{c|}{ II } & III & IV & TOTAL \\
\hline Fundamentos teóricos e metodológicos & 12 & 5 & 10 & 12 & 39 \\
\hline Aspectos pedagógicos & 0 & 1 & 4 & 6 & 11 \\
\hline Formação de educadores & 1 & 1 & 1 & 2 & 5 \\
\hline Movimentos sociais & 1 & 0 & 0 & 2 & 3 \\
\hline Outros & 2 & 1 & 0 & 2 & 5 \\
\hline
\end{tabular}

Em se tratando dos trabalhos de natureza empírica que se referem ao contexto escolar (Tabela 7A), verifica-se a predominância de dois focos temáticos: o desenvolvimento de projetos, programas e práticas escolares e as concepções, percepções, visões ou memórias de estudantes e professores. Há poucos trabalhos que analisam as relações entre atividades de EA e os meios de comunicação e entre a EA e as teorias curriculares. A lacuna existente em relação às teorias curriculares deve ser considerada em nossas políticas educacionais e curriculares, já que estas podem oferecer instrumentos para compreender necessidades e perspectivas para as práticas educacionais ambientais.

$\mathrm{O}$ foco temático materiais pedagógicos para a EA ainda aparece timidamente nesses trabalhos, dado também constatado por Pato, Sá e Catalão (2009). Cabe salientar a importância de divulgarmos os resultados de pesquisas 
que investigam tais materiais para professores e educadores, oferecendo elementos para que estes possam analisar e selecionar recursos que atendam aos seus interesses e respondam às expectativas de diferentes perspectivas de EA. Um dado que merece ser destacado diz respeito a trabalhos que abordam a articulação de processos educativos em contextos escolares com atividades de EA desenvolvidas em unidades de conservação, que aparecem de modo significativo. Apesar disso, outros espaços não formais de ensino não aparecem nesses trabalhos sobre contextos escolares. Considerando que as atividades de campo e as atividades extraclasse são formas motivadoras no tratamento de temas ambientais e que esses procedimentos pedagógicos são valorizados tanto por ambientalistas quanto por educadores e professores, esperava-se encontrar um número mais significativo desses trabalhos.

Tabela 7 - Focos temáticos dos trabalhos de natureza empírica em distintos contextos educacionais.

\begin{tabular}{|c|c|c|c|c|c|}
\hline \multicolumn{2}{|c|}{$\begin{array}{c}\text { (A) EM CONTEXTOS } \\
\text { ESCOLARES }\end{array}$} & \multicolumn{2}{c|}{$\begin{array}{c}\text { (B) EM CONTEXTOS } \\
\text { NÃO ESCOLARES }\end{array}$} & \multicolumn{2}{c|}{ (C) GENÉRICOS } \\
\cline { 1 - 3 } $\begin{array}{c}\text { Programas e projetos } \\
\text { escolares }\end{array}$ & 46 & EA e comunidades & 24 & $\begin{array}{c}\text { Processos formativos } \\
\text { e concepções de } \\
\text { professores e } \\
\text { educadores }\end{array}$ & 14 \\
\cline { 1 - 3 } $\begin{array}{c}\text { Percepção, concepções } \\
\text { e memória }\end{array}$ & 31 & $\begin{array}{c}\text { Mídias e recursos } \\
\text { didáticos }\end{array}$ & 11 & \multirow{2}{*}{$\begin{array}{c}\text { Estudos do tipo } \\
\text { estado da arte }\end{array}$} & 5 \\
\hline Práticas escolares & 23 & Avaliação de programas & 11 & \\
\hline Materiais pedagógicos & 12 & $\begin{array}{c}\text { EA a áreas de unidade de } \\
\text { conservação }\end{array}$ & 9 & & \\
\hline Outros & 7 & $\begin{array}{c}\text { Percepção, concepções e } \\
\text { memória }\end{array}$ & 9 & & \\
\hline Estudos curriculares & 9 & Outros & 4 & & \\
\hline Unidades de & 9 & EA e regionalismos & 5 & & \\
\hline conservação & 7 & Políticas públicas & 3 & & \\
\hline Propostas curriculares & 2 & EA e ONGs & 3 & & \\
\hline Meios de comunicação & 2 & EA e ecoturismo & 3 & & \\
\hline
\end{tabular}

$\mathrm{Na}$ análise de trabalhos empíricos relacionados a contextos não escolares (Tabela 7B), verifica-se que o foco temático mais enfatizado pelos pesquisadores são as práticas em EA desenvolvidas em comunidades. Trabalhos que analisam programas e projetos em EA conduzidos em contextos não escolares e práticas de EA em áreas de conservação são também representativos. Por outro lado, verifica-se um número ainda pequeno de trabalhos enfocando políticas públicas em EA. Observou-se também que há poucos trabalhos sobre práticas em EA conduzidas por ONGs, ligadas ao ecoturismo e realizadas em museus, zoológicos e jardins botânicos. 
Entre os trabalhos de natureza empírica que foram aqui classificados como genéricos, observa-se uma grande expressividade daqueles que versam sobre os processos formativos e concepções de professores e educadores e daqueles que analisam as pesquisas na área na forma de estudos do tipo "estado da arte" e outros tipos de estudo, os quais vêm crescendo de forma progressiva nos últimos eventos, evidenciando a busca de um olhar reflexivo para a produção do próprio campo (AVANZI; SILVA, 2004; BOER, 2007; VALENTIM, 2004; ZAKRZEVSKI; DEFACCI; LOSEKANN, 2006). Esse mesmo movimento reflexivo é encontrado em textos de autores de outros países, configurando um movimento internacional na primeira década do presente século (BENAYAS; GUTIÉRREZ; HERNÁNDEZ, 2003; BRAVO MERCADO, 2003; GAYFORD, 2001; PAYNE, 2009; SAUVÉ, 2000). Segundo Hart:

Tendo em conta que as metodologias de pesquisa se desenvolvem para abarcar mais do que dimensões cognitivas de questões complexas, atingindo uma variedade de perspectivas mais sensíveis às relações de poder, às emoções, à construção da experiência e às questões de posicionamentos de valores culturais e morais, a investigação em EA parece estar adquirindo características de reflexividade crítica que indicam certa maturidade do campo (HART, 2009, p. 169).

\section{Considerações finais}

O número significativo de textos não aprovados nos EPEAs, por estes não se enquadrarem no escopo dos eventos e/ou por não apresentarem elementos suficientes para sua configuração como "pesquisa em educação ambiental", demonstra que ainda há um longo caminho a percorrer nesta trajetória rumo à constituição de um campo de pesquisa nessa área (FREITAS; OLIVEIRA, 2006). Temos percebido a necessidade de aprofundar o debate, tanto entre nós como com nossos pares, de uma questão que está distante de ser consensual: quais critérios usar para classificar uma pesquisa como pesquisa em EA? Quais critérios usar para distinguir pesquisas de relatos de experiência? Como socializar para o amplo e diversificado corpo de pareceristas os níveis de consenso que temos alcançado como grupo organizador? Apesar de termos avançado na definição desses critérios desde a primeira edição do EPEA, a dificuldade na categorização de uma parcela dos trabalhos permanece. Nos casos de trabalhos em que nossas posições eram divergentes, foi necessário um processo de diálogo no grupo para encontrar níveis de consenso mínimo e então proceder ou não ao encaminhamento de trabalhos para pareceristas para um parecer detalhado. Portanto, defendemos a importância da ampliação desse debate sobre as características dos trabalhos que engendram dúvidas, discutindose tanto os critérios gerais quanto aqueles baseados em casos concretos. 
A presença significativa de trabalhos de natureza empírica e de contextos educacionais escolares, sobretudo focados na educação básica, com focos temáticos voltados para esses mesmos contextos, demonstra que a educação escolar é ainda o principal locus dessas pesquisas. Resultados similares, encontrados em eventos de pesquisa em ensino de ciências (KAWASAKI et al., 2009) e em eventos educacionais, tais como as reuniões anuais da Associação Nacional de Pesquisa e Pós-Graduação em Educação (ANPEd) e os Encontros de Pesquisa em Educação Ambiental (EPEAs) (CARVALHO; SCHMIDT, 2008), vêm corroborar essa tendência. A razão para isso pode estar relacionada às características desses eventos e ao perfil de seus participantes, conforme já mencionado. Outra explicação para a predominância das pesquisas nos contextos escolares poderia ser buscada na história da educação, que só recentemente vem integrando conteúdos relativos aos contextos não escolares às suas discussões e aos currículos dos cursos de formação de professores. Se juntarmos a essa constatação a forte crença que os educadores costumam ter no papel da escola como uma das instituições que podem colaborar de forma particular para as transformações sociais, encontraremos mais uma razão para as escolhas dos pesquisadores.

A ênfase em fundamentos teóricos e metodológicos da EA encontrada nos trabalhos de natureza teórica e reflexiva, uma tendência que vem crescendo nos EPEAs e nos eventos científicos da área educacional, foi avaliada positivamente pelos organizadores, já que vai ao encontro do desejo da comunidade científica em EA de um delineamento mais claro de um corpo de conhecimentos que sejam próprios desse campo de pesquisa. Carvalho e Schmidt (2008), ao analisarem as pesquisas apresentadas na ANPEd e no próprio EPEA (em especial no III EPEA), identificaram o predomínio de trabalhos relacionados à discussão de bases teóricas e metodológicas de propostas, práticas e concepções de EA. Tais trabalhos tiveram em comum a filiação da EA a certas tradições teóricas, conceitos e autores específicos, buscando o aprofundamento da compreensão e/ou construção de fundamentos epistemológicos da EA. A mesma tendência foi encontrada em periódicos relacionados à pesquisa em EA, conforme apontam Kawasaki e Carvalho (2009).

Já a ênfase em programas, projetos e práticas escolares (contexto escolar) e em comunidades (contexto não escolar) em trabalhos de natureza empírica demonstra que as ações e práticas voltadas para a EA são ainda muito frequentes nessa área. Talvez o compromisso político de muitos educadores ambientais, construído nas práticas e presentes quando estes se tornam pesquisadores em EA, possa também explicar essa preponderância nos trabalhos de natureza empírica, que representam olhares para realidades nas quais atuam ou atuaram, em busca de transformações. Tais preocupações com realidades mais voltadas para a sala de aula e 
o interior da escola representam uma tendência presente nas pesquisas em educação desde a década de 1980 (LUDKE; ANDRÉ, 1986), quando as questões que os pesquisadores começaram a colocar passaram a advir de problemas revelados pela prática educacional. O desafio que se coloca para esse tipo de trabalhos é que possam superar o formato do relato simples e descritivo, buscando maior aprofundamento e reflexão sobre as ações, à luz de referenciais teóricos que permitam produzir conhecimentos na área e aperfeiçoar as ações educativas.

Freitas e Oliveira (2006), a partir da perspectiva de uma EA crítica e transformadora da sociedade, apontam os diversos espaços sociais para além da escola, como a EA não escolar e a EA comunitária, como importantes espaços formativos. Carvalho e Schmidt (2008), ao analisarem os trabalhos da ANPPAS (Associação Nacional de Pós-Graduação e Pesquisa em Ambiente e Sociedade), verificaram que a temática que isoladamente agregou maior número de trabalhos foi a EA popular, em geral relacionada a intervenções comunitárias em espaços não formais, o que parece ser congruente com a própria conformação da ANPPAS e de seu Grupo de Trabalho (GT) Educação, Meio Ambiente e Sociedade. Porém, quando Carvalho e Schmidt (2008) agregaram as temáticas, verificaram que a preocupação com a EA nos espaços formais de ensino é uma constante nos três eventos estudados (ANPPAS, ANPEd e EPEA). Nos EPEAs o que verificamos foi uma quase ausência de trabalhos que abordam a EA em espaços não escolares, como em ONGs, zoológicos, jardins botânicos, áreas urbanas, comunidades, associações de bairros, entre outros, ou envolvendo educadores que atuam na educação não formal. Assim, entendemos que pesquisas como as da chamada EA popular têm um amplo espaço a ser ocupado nos EPEAs.

Por fim, cabe reforçar o alerta para o fato de que no interior da comunidade científica desse campo de pesquisa há uma ampla heterogeneidade e alto grau de polissemia na interpretação do que seja ambiental, educação ambiental e pesquisa de qualidade em educação ambiental, dado que se trata de um campo bastante novo e emergente. Esse alerta também é feito por Sauvé (2000) e Hart (2009). Sendo assim, deixamos aqui um convite e um desafio para os pesquisadores: buscar conjuntamente critérios de qualidade que, sem aprisionar, possam contribuir, de um lado, para a produção de pesquisas com relevância social, acadêmica e científica e, de outro, para o aperfeiçoamento da própria prática da educação ambiental.

\section{Referências}

AVANZI, Maria Rita; SILVA, Rosana Louro Ferreira. Traçando os caminhos da pesquisa em Educação Ambiental: uma reflexão sobre o II EPEA. QUAESTIO, Revista de Estudos de Educação, v. 6, n. 1, p. 123-132, maio 2004. 
BARDIN, Laurence. Análise de Conteúdo. Lisboa: Edições 70, 1977.

BENAYAS, Javier; GUTIÉRREZ, José; HERNÁNDEZ, Norma. La investigación en Educación Ambiental en España. Madrid: Ministerio de Medio Ambiente - Secretaría General de Medio Ambiente; Organismo Autónomo Parques Nacionales, 2003. 176 p. (Serie Educación Ambiental).

BOER, Noemi. Educação Ambiental e visões de mundo: uma análise pedagógica e epistemológica. 2007. 216 f. Tese (Doutorado em Educação Científica e Tecnológica) Universidade Federal de Santa Catarina, Florianópolis, 2007.

BRAVO MERCADO, Maria Teresa. La investigación en Educación y Medio Ambiente. In: BERKELY-BUSQUETS, Maria (Coord.). Educación, Derechos sociales y Equidad. México: COMIE-SEP-ESU, 2003. p. 277-369. (Tomo 1).

CARVALHO, Isabel Cristina de Moura; SCHMIDT, Leticia Santos. A pesquisa em Educação Ambiental: uma análise dos trabalhos apresentados na ANPED, ANPPAS e EPEA de 2001 a 2006. Pesquisa em Educação Ambiental, Ribeirão Preto, v. 3, n. 2, p. 147174, jul./dez. 2008.

CARVALHO, Luiz Marcelo; TOMAZELLO, Maria Guiomar Carneiro; OLIVEIRA, Haydée Torres de. Pesquisa em Educação Ambiental: panorama da produção brasileira e alguns de seus dilemas. Cad. CEDES, Campinas, p. 13-27, jan./abr. 2009.

CAVALARI, Rosa Maria Feiteiro; SANTANA, Luiz Carlos; CARVALHO, Luiz Marcelo. Concepções de educação e Educação Ambiental nos trabalhos do I EPEA. Pesquisa em Educação Ambiental, São Carlos, v. 1, n. 1, p. 141-173, jul./dez. 2006.

DEMO, Pedro. Pesquisa e construção do conhecimento: metodologia científica no caminho de Habermas. Rio de Janeiro: Tempo Brasileiro, 1994.

. Metodologia do conhecimento científico. São Paulo: Atlas, 2000.

FRACALANZA, Hilário. As pesquisas sobre educação ambiental no Brasil e as escolas: alguns comentários preliminares. In: TAGLIEBER, José Erno; GUERRA, Antonio Fernando Silveira (Org.). Pesquisa em educação ambiental: pensamentos e reflexões de pesquisadores em educação ambiental. Pelotas: Universitária, 2004.

FRACALANZA, Hilário et al. A educação ambiental no Brasil: panorama inicial da produção acadêmica. In: ENCONTRO DE PESQUISA EM EDUCAÇÃO EM CIÊNCIAS, 5., 2005, Bauru. Anais... Bauru: ABRAPEC, 2005. 1 CD-ROM.

FREITAS, Denise de; OLIVEIRA, Haydée Torres de. Pesquisa em educação ambiental: um panorama de suas tendências metodológicas. Pesquisa em Educação Ambiental, São Carlos, v. 1, n. 1, p. 175-191, jul./dez. 2006.

GAYFORD, Chris. Trends in Environmental Education Research in England. Educação: teoria e prática, v. 9, n. 16-17, p. 17-23, 2001.

GRANDINO, Débora Regina. A pesquisa em educação ambiental no Brasil: período 2002-2005. Piracicaba: UNIMEP, 2007. Disponível em <http://www.unimep.br/phpg/ mostraacademica/anais/5mostra/backup/1/229.pdf>. Acesso em: 12 jan. 2010.

HART, Paul. Em resposta a "isto não é bom o suficiente": reflexões sobre a pesquisa em Educação Ambiental no Canadá em contextos de expansão. Educação em Revista, Belo Horizonte, v. 25, n. 3, p. 159-190, dez. 2009. 
KAWASAKI, Clarice Sumi; MATOS, Mauricio dos Santos; MOTOKANE, Marcelo Tadeu. O perfil inicial do pesquisador em educação ambiental: elementos para um estudo sobre a constituição de um campo de pesquisa em educação ambiental. Pesquisa em Educação Ambiental, São Carlos, v. 1, n. 1, p. 111-140. jul./dez. 2006.

KAWASAKI, Clarice Sumi et al. A Pesquisa em Educação Ambiental nos ENPECs: contextos educacionais e focos temáticos. ENCONTRO NACIONAL DE PESQUISADORES EM EDUCAÇÃO EM CIÊNCIAS, 7., 2009. Florianópolis. Anais... Florianópolis: UFSC, 2009.

KAWASAKI, Clarice Sumi; CARVALHO, Luiz Marcelo de. Tendências da pesquisa em Educação Ambiental. Educação em Revista, Belo Horizonte, v. 25, n. 3, p. 143-157, dez. 2009. Disponível em <http://www.scielo.br/scielo.php?script=sci_arttext\&pid=S010246982009000300008\&lng=pt\&nrm=iso\&tlng=pt>. Acesso em: 15 jan. 2010.

LÜDKE, Menga; ANDRÉ, Marli E. D. A. Pesquisa em educação: abordagens qualitativas. São Paulo: EPU, 1986.

PATO, Cláudia; SÁ, Lais Mourão; CATALÃO, Vera Lessa. Mapeamento de tendências na produção acadêmica sobre Educação Ambiental. Educação em Revista, Belo Horizonte, v. 25, n. 3, p. 213-224, dez. 2009. Disponível em <http://www.scielo.br/scielo.php? script $=$ sci_arttext\&pid=S0102-46982009000300011\&lng=pt\&nrm=iso\&tlng=pt $>$.

Acesso em: 15 jan. 2010.

PAYNE, Phillip. Configuration of the field of research in Environmental Education: a critical summary. Pesquisa em Educação Ambiental, São Carlos, v. 4, n. 2, p. jul./dez. 2009.

REIGOTA, Marcos. O estado da arte da pesquisa em educação ambiental no Brasil. Pesquisa em Educação Ambiental, Ribeirão Preto, v. 2, n. 1, p. 33-66, jan./jun. 2007.

SAUVÉ, Lucie. Para construir un patrimonio de investigación en educación ambiental. Tópicos en Educación Ambiental, v. 2, n. 5, p. 51-69, 2000.

TOMAZELLO, Maria Guiomar Carneiro. Reflexões acerca das dissertações e teses brasileiras em educação ambiental do período 1987-2001. Enseñanza de las Ciencias, Barcelona, v. 23, n. extra, p. 1-6, 2005. CD-ROM.

VALENTIM, Leirí. Tendências das pesquisas em Educação Ambiental no Brasil: algumas considerações. In: REUNIÃO ANUAL DA ASSOCIAÇÃO NACIONAL DE PÓS-GRADUAÇÃO EM EDUCAÇÃO, 27., 2004. Caxambu. Anais... Caxambu: ANPEd, 2004. Disponível em: <http://www.anped.org.br/reunioes/27/gt22/p221. pdf>. Acesso em: 18 abr. 2009.

ZAKRZEVSKI, Sônia; DEFACCI, Ângela Camila; LOSEKANN, Cassineli Carneiro. A pesquisa em Educação Ambiental nos programas de pós-graduação stricto sensu: um estudo nas universidades gaúchas. UNIrevista, São Leopoldo, v. 1, n. 2, abr. 2006.

Artigo: recebido em 24/11/2009 - aprovado em 21/12/2009. 